\title{
EFFECT OF WELDING CURRENT AND ELECTRODES ON WELD WIDTH IN SHIELDED METAL ARC WELDING PROCESS
}

\author{
AJIT KUMAR YADAV ${ }^{1}$ MANOJ KUMAR AGRAWAL ${ }^{2}$ \& RUDRA PRATAP SINGH ${ }^{3}$ \\ ${ }^{I}$ Research Scholar, Mechanical Engineering Department, GLA University, Mathura \\ ${ }^{2,3}$ Associate Professor, Department of Mechanical Engineering' GLA University, Mathura, India
}

\begin{abstract}
Shielded metal arc welding process is a simple and a commonly used method of joining materials. The weld widthis an important macroscopic welding output parameter whch affects the mechanical properties of the weld. In the present work the investigation of the effect of three different types of electrodes at three different welding currents in shielded metal arc welding process utilizingLow Carbon Steel plate of API 5L Grade X 52, was done. The three different electrode were used as E 6013, E 7016 and E 7018 and the varying currents utilized were as 90 A, $100 \mathrm{~A}$ and $110 \mathrm{~A}$. Total 9 pairs of work pieces were welded to obtain 9 welds which were used to analyze the effect of current and the electrode on the depth of penetration. The dimensions of the work pieces utilized were as $75 \mathrm{~mm} \times 50 \mathrm{~mm} \times 5 \mathrm{~mm}$. The values of weld width in each weld were written in a table and respective diagrams were drawn to make clear the effect of welding current on weld width for different electrodes. It was found that weld width decreased for all the cases of electrodes if the value of current was increased.
\end{abstract}

KEYWORDS: Electrode, Current, Structure, Weld Width, Arc.

Received: Jun 05, 2020; Accepted: Jun 25, 2020; Published: Jun 30, 2020; Paper Id.: IJMPERDJUN2020329

\section{INTRODUCTION}

The welding current is responsible for creation of heat for welding. Optimum design of welds for sufficient mechanical properties is being investigated by several researchers from several decades but joints fail during work. The weld width of the weld is a macro-structural property of the weld which indirectly governs the mechanical properties of the weld. In several industries shielded metal arc welding process is used for making joints. The shielded metal arc welding process is simple and cheap and can be operated easily by human welders in a very small working area. Heat and pressure both or any one alone can be applied to join structural parts in any welding process. Two or more parts of any structural member can be joined by many methods but the shielded metal arc welding process develops quite reliable, strong enough, cost effective joint. The welds are light in weight hence this process is preferred over many other joining processes [1]. The life of welded parts can be improved by including some special materials in the weld with the help of electrode. The shielded metal arc welding process is manually operated hence it is also known as manual metal arc welding process [2]. A core wire which is generally made of the material,from which the work piece is formed, is used for the formation of electrode. This core wire is surrounded by some coatings containing required materials. The electrode is consisted of different types of filler material and is made in different sizes of length and diameter. When the electrode melts, the filler materials also melt with the base material and become the part of the weld and hence improve the properties of the joint. Due to the burning of the filler material some gasses are produced which are utilized to shield and protect the molten weld 
from the surrounding atmospheric gasses [3]. The coating of the electrode also contains some flux which reacts with the impurities present in the base metal and forms some slag which has low density. Due to low density of the slag, it floats on the upper layers of the molten weld, which is removed from the surface of when it is solidified [4]. The electrode and the work pieces are used as positive and negative terminals of the electric circuit in SMAW process with the help of some cables. The process develops a temperature of about 5000 degree centigrade in between the tip of the electrode and the work-piece. The heat produced is very high and is capable to melt the electrode, coatings, filler materials and base material to form the weld [5]. Alternative current or direct current can be used for the process. In India the alternative current has a frequency of $50 \mathrm{~Hz}$ which implies that the arc extinguishes 100 times in a minute, the re-establishment of the arc can be obtained by some special electrodes. There are several types of electrodes which serve this purpose, but some electrodes like E 6013, E 7016 and E 7018 are very important. E 6013 electrode generally produces a soft arc with very smallspatter. It develops moderate penetration and has an easily-removable slag. This electrode should be used to obtain a weld which is clean and strong. The electrode E 7016 is basic coatedhydrogen controlled electrode for welding grey cast iron components, medium and high tensile structures and low and medium carbon steels. The deposits have radiographic quality with excellent mechanical properties. The electrode E 7018 is a low-hydrogen type electrode which reduces hydrogen embrittlement in the weldment[6]. The weld width is a very important macro-structural property of the weld which actually indicates the mechanical properties of the weld and increases the life of the structure if properly designed.

\section{EXPERIMENTAL PROCEDURE}

The experiments were performed in the welding science and technology lab of the GLA University, Mathura. The welding of specimens was done with the help of a shielded metal arc welding process. Total nine pairs of specimen pieces were cut from a large Low Carbon Steel plate of API 5L Grade X 52having $50 \mathrm{~mm}$ width and $5 \mathrm{~mm}$ thickness, with the help of a power hack saw. The chemical composition of Low Carbon Steel plate of API 5L Grade X 52 is shown in table 1. The dimensions of the specimens were taken as $75 \mathrm{~mm} \times 50 \mathrm{~mm} \times 5 \mathrm{~mm}$. The specimens were cleaned with the help of rough and hard papers to remove rust, dust and contaminated surface layers. Two pieces forming a pair were welded in butt position to obtain the required bead. The used power source was a shielded metal arc welding machine using transformer, from which the power was supplied to the work pieces with the help of an electrode. An electric arc was developed in between the work piece and the electrode. The energy was supplied through the arc and a column of highly ionized gas and metal vapours. The temperature of about $5000^{\circ} \mathrm{C}$ was developed in this welding process. The high amount of heat, so developed was used to melt the material and to form the joint. The measurement of bead dimensions by metallurgical microscope is shown in figure 1.

In this work three types of electrodes namely E 6013, E 7016 and E 7018 were used at welding currents of 90 A, $100 \mathrm{~A}$ and $110 \mathrm{~A}$. Each electrode has $3.15 \mathrm{~mm}$ as diameter and the former has $350 \mathrm{~mm}$ length and the other two have the length as $450 \mathrm{~mm}$. The chemical composition of E 6013, E 7016 and E 7018 are shown in tables 2, 3 and 4 respectively. Every electrode was used to weld three pairs of specimens using currents $90 \mathrm{~A}, 100 \mathrm{~A}$ and $110 \mathrm{~A}$, respectively. The other input welding parameters were kept at constant values as $22 \mathrm{~V}$ voltage, $6.35 \mathrm{~mm} / \mathrm{s}$ as feed rate and welding speed as 1.44 $\mathrm{mm} / \mathrm{s}$. 


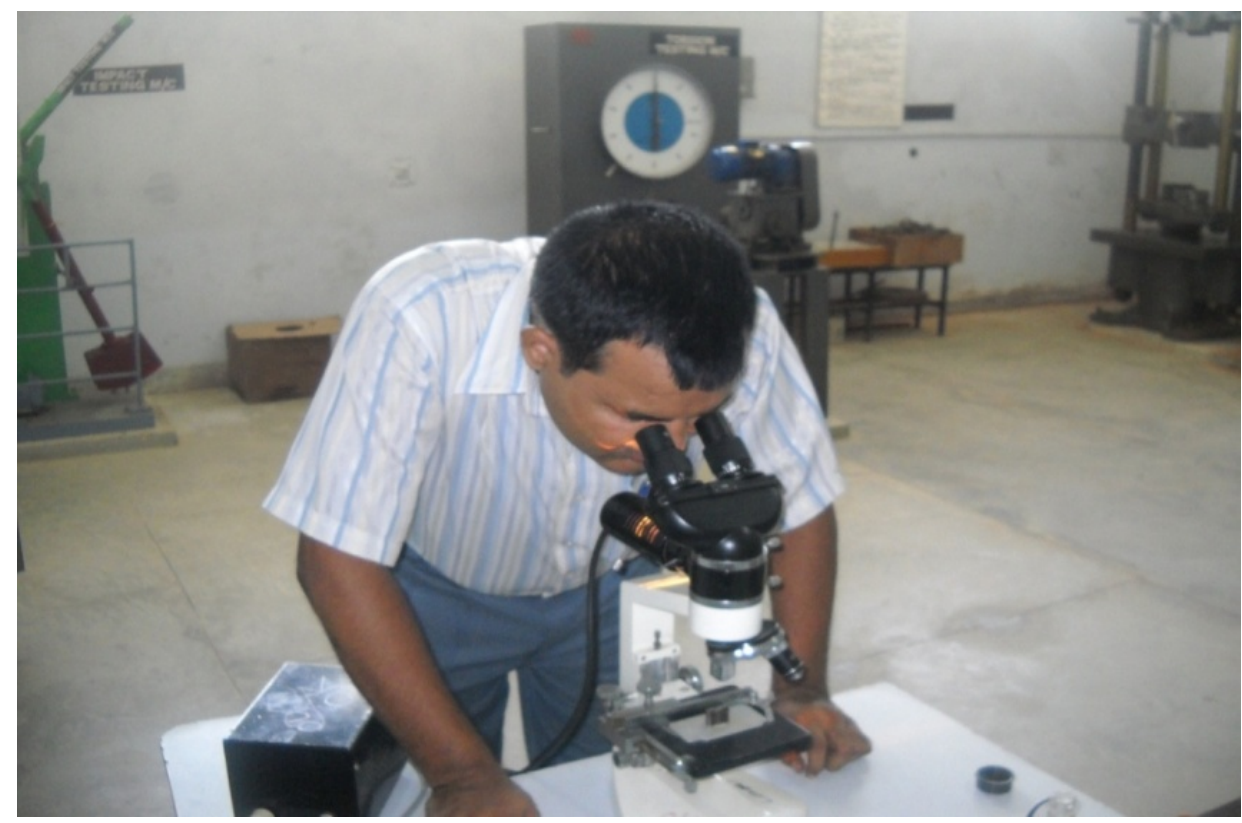

Figure 1: Measurement Of Weld Bead Dimensions With Metallurgical Microscope

The values of weld width for every weld were recorded in table 5. After welding, all the weld beads obtained were sectioned transversely at two surfaces in such a way that middle portion, $1 \mathrm{~mm}$ thick containing weld, heat affected zone and base metal were selected for investigation. The welds are generally not proper at start and at end of the work pieces due to several reasons so these portions are removed. The sectioned parts were ground with the help of emery belt grinders of grades 0, 2 and 3 so that weld bead dimensions become clear and visible. The ground portions were polished with double disk polishing machine. Etching process was done to the polished pieces with the help of a mixture of $2 \%$ nitric acid and $98 \%$ ethyl alcohol solution. The depth of penetration was measured for every weld with the help of metallurgical microscope and digital sliding calliper and arranged in table 5. The effect of welding current and electrode on weld width can be easily analyzed with this table.

\section{RESULT AND DISCUSSIONS}

Table 1:Chemical Composition of Work-piece Material as Low Carbon Steel API 5L Grade X 52

\begin{tabular}{|c|c|c|c|c|c|}
\hline Element & C & Mn & P & S & Fe \\
\hline \%age Composition & $\mathbf{0 . 2 0}$ & $\mathbf{1 . 3 5}$ & $\mathbf{0 . 0 2 5}$ Max & $\mathbf{0 . 0 0 1}$ Max & Remaining (98.484) \\
\hline
\end{tabular}

Table 2: Chemical Composition of E 6013

\begin{tabular}{|c|c|c|c|c|c|}
\hline Element & $\mathrm{C}$ & $\mathrm{Mn}$ & $\mathrm{Cr}$ & $\mathrm{Si}$ & Element \\
\hline \%age Composition & $\mathbf{0 . 0 8}$ & $\mathbf{0 . 5}$ & $\mathbf{0 . 0 6}$ & $\mathbf{0 . 3 0}$ & \%age Composition \\
\hline
\end{tabular}

Table 3: Chemical Composition of E 7016

\begin{tabular}{|c|c|c|c|c|c|}
\hline Element & $\mathrm{C}$ & $\mathrm{Mn}$ & $\mathrm{Cr}$ & $\mathrm{Si}$ & Element \\
\hline \%age Composition & $\mathbf{0 . 1 0}$ & $\mathbf{0 . 9 0}$ & $\mathbf{0 . 1 4}$ & $\mathbf{0 . 7 0}$ & \%age Composition \\
\hline
\end{tabular}

Table 4: Chemical Composition of E 7018

\begin{tabular}{|c|c|c|c|c|c|}
\hline Element & $\mathrm{C}$ & $\mathrm{Mn}$ & $\mathrm{Cr}$ & $\mathrm{Si}$ & Element \\
\hline \%age Composition & $\mathbf{0 . 9 0}$ & $\mathbf{1 . 1 0}$ & $\mathbf{0 . 1 0}$ & $\mathbf{0 . 6 0}$ & \%age Composition \\
\hline
\end{tabular}


Table 5: Variation of Weld Width with Welding Current using Different Electrodes

\begin{tabular}{|c|c|c|c|}
\hline $\mathbf{S N}$ & Electrode & Current (A) & $\mathbf{W W}(\mathbf{m m})$ \\
\hline 1 & \multirow{3}{*}{ E 6013} & 90 & 9.77 \\
\hline 2 & & 100 & 9.67 \\
\hline 3 & & 110 & 9.47 \\
\hline 4 & \multirow{3}{*}{ E 7016} & 90 & 9.03 \\
\hline 5 & & 100 & 8.90 \\
\hline 6 & & 110 & 8.73 \\
\hline 7 & \multirow{3}{*}{ E 7018} & 90 & 9.96 \\
\hline 8 & & 100 & 9.90 \\
\hline 9 & & 110 & 9.81 \\
\hline
\end{tabular}

3.1 Variation of Weld Width with Welding Current using E 6013 Electrode

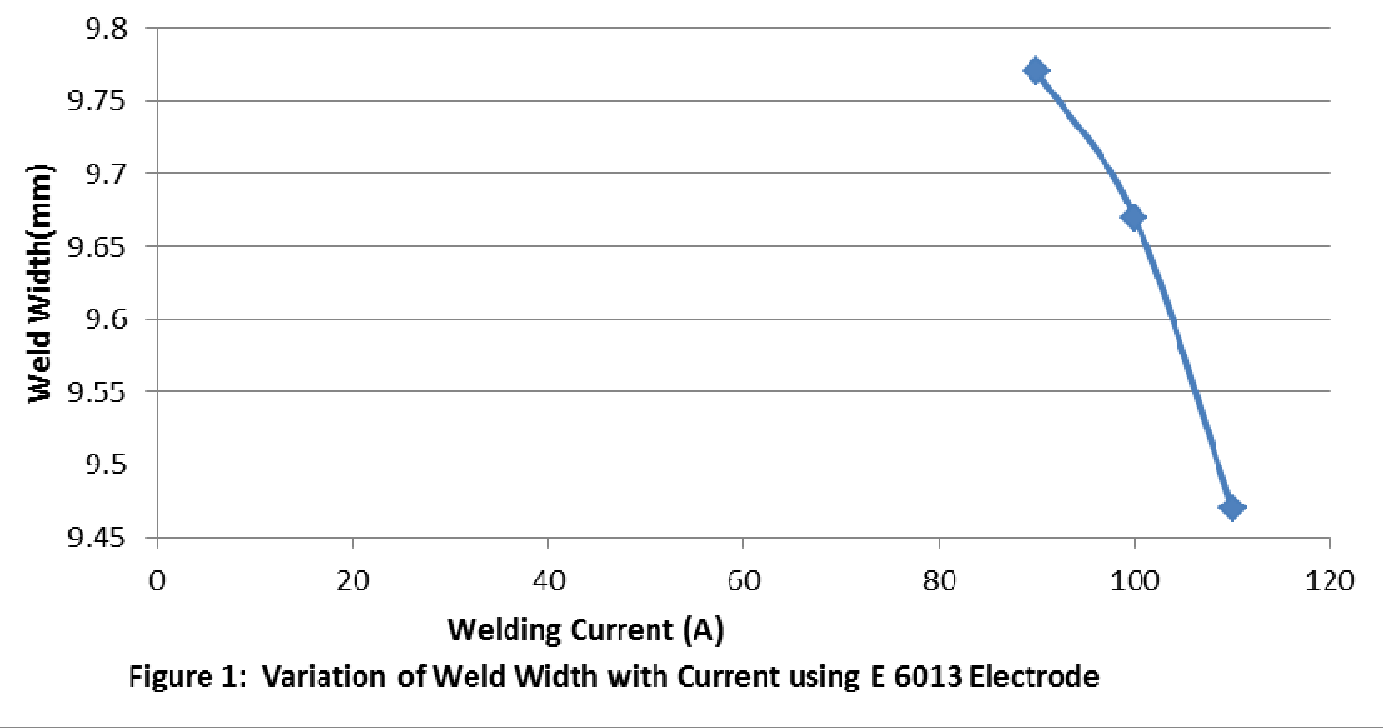

The weld width for electrode E 6013 decreases with increase in current for the whole experimental range as shown in figure 1. At 90 A current the weld width was found to be $9.77 \mathrm{~mm}$, when the current was increased to $100 \mathrm{~A}$ the weld width decreased to $9.67 \mathrm{~mm}$ and when the current was again increased to $110 \mathrm{~A}$ the weld width also again decreased to $9.47 \mathrm{~mm}$. With the increase of the current the net heat input increases hence melt volume also increases which implies that depth of penetration, weld width and reinforcement height should increase but if weld width is decreasing, it indicates that either depth of penetration or reinforcement height or both increased more to compensate the reduction in weld width. 


\subsection{Variation of Weld Width with Welding Current using E 7016 Electrode}

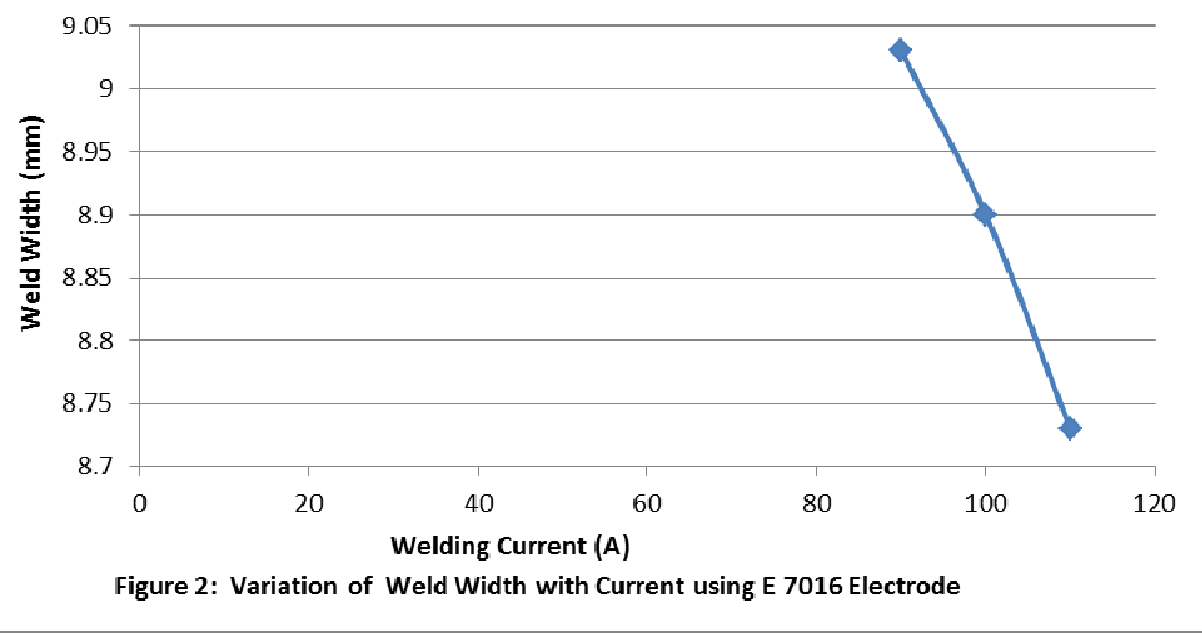

The weld width for electrode E 7016 decreases with increase in current for the whole experimental range as shown in figure 2. At 90 A current the weld width was found to be $9.03 \mathrm{~mm}$, when the current was increased to $100 \mathrm{~A}$ the weld width decreased to $8.90 \mathrm{~mm}$ and when the current was again increased to $110 \mathrm{~A}$ the weld width also again decreased to $8.73 \mathrm{~mm}$. With the increase of the current the net heat input increases hence melt volume also increases which implies that depth of penetration, weld width and reinforcement height should increase but if weld width is decreasing, it indicates that either depth of penetration or reinforcement height or both increased more to compensate the reduction in weld width.

\subsection{Variation of Weld Width with Welding Current using E 7018 Electrode}

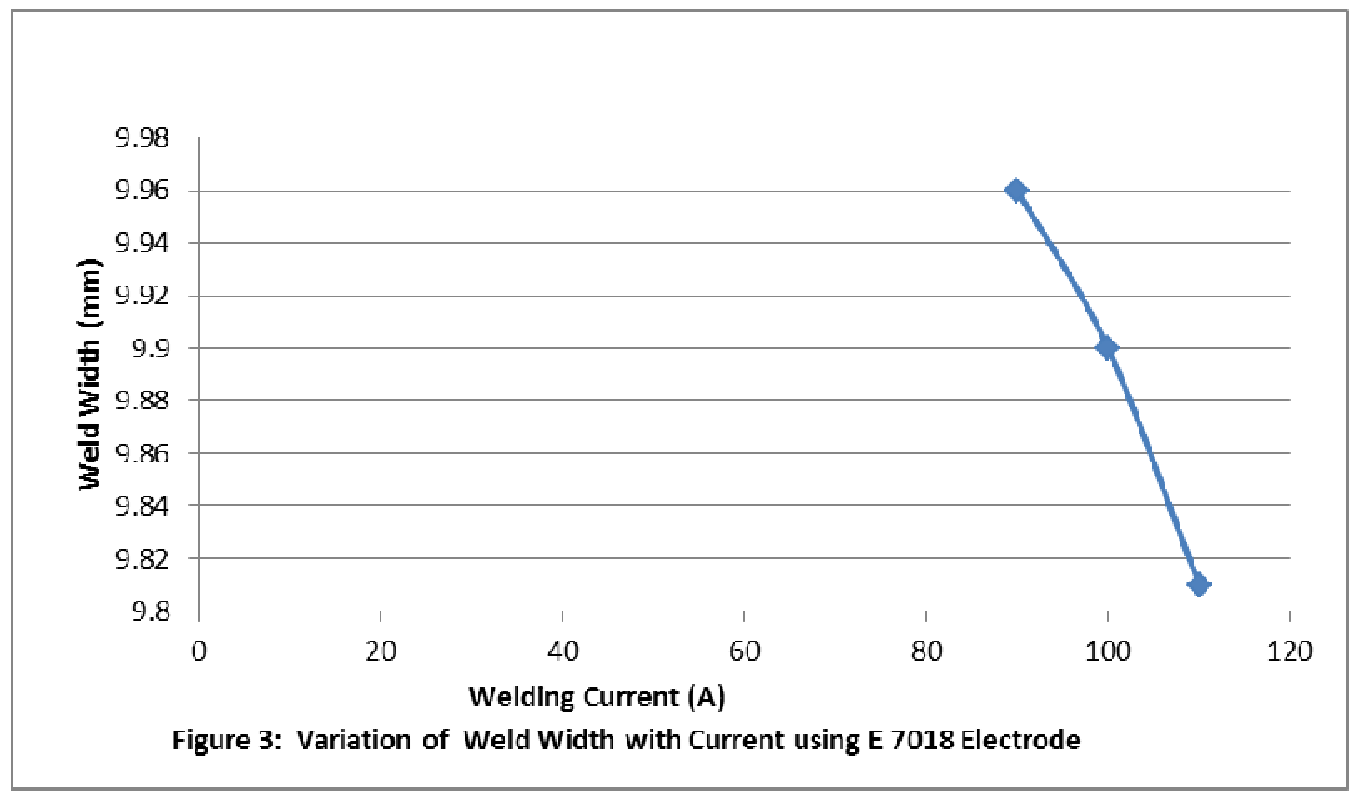

The weld width for electrode E 7018 decreases with increase in current for the whole experimental range as shown in figure 3. At 90 A current the weld width was found to be $9.96 \mathrm{~mm}$, when the current was increased to 100 A the 
weld width decreased to $9.90 \mathrm{~mm}$ and when the current was again increased to $110 \mathrm{~A}$ the weld width also again decreased to $9.81 \mathrm{~mm}$. With the increase of the current the net heat input increases hence melt volume also increases which implies that depth of penetration, weld width and reinforcement height should increase but if weld width is decreasing, it indicates that either depth of penetration or reinforcement height or both increased more to compensate the reduction in weld width.

\section{CONCLUSIONS}

Following conclusions can be drawn from the experiments performed.

- The weld width depends upon the current used for welding.

- As the current is increased the weld width decreases for whole range of experiments for all types of electrodes applied in the experiments.

- The maximum value of weld width was found to be $9.96 \mathrm{~mm}$ using E 7018 electrode at $90 \mathrm{~A}$ welding current.

- The minimum value of weld width was found to be $9.47 \mathrm{~mm}$ using E 6013 electrode at $110 \mathrm{~A}$ welding current.

\section{FUTURE SCOPE}

Following are recommendations for future study:

- (1)The experiment was performed for low carbon steel, using only three types of electrodes, which can be extended to other materials using many other electrodes also.

- (2)In this experiment the process of welding utilized was the shielded metal arc welding process, other processes like submerged arc welding and tungsten inert gas welding processes etc. can also be used.

- (3)The range of current was limited from 90A to 110A; it can be increased for better exposure of the trend of depth of penetration with the change of welding current.

- (4)Artificial neural networks, Taguchi methods etc can be used to make clearer the study.

\section{REFERENCES}

1. Kim I. S., Son J. S., Park C. E. and Kim I. J., Kim H. H. (2005) An investigation into an intelligent system for predicting bead geometry in GMA welding process. Journal of Materials Processing Technology. 159 (2005) $113-118$.

2. Tewari S. P., Ankur Gupta and JyotiPrakash (2010). Effect of welding parameters on the weldability of materials. International journal of engineering science and technology volume 2(4), 512-516.

3. Bahman, A.R. (2010). Change in Hardness, Yield Strength and UTS of Welded Joints Reduced in ST 37 Grade Steel. Indian Journal of Science and technology, 1162-1164.

4. Abson, D. J., \&Pargeter, R. J. (2013). Factors influencing as-deposited strength, microstructure, and toughness of manual metal arc welds suitable for C-Mn steel fabrications. International Metals Reviews, 31(1), 141-196.

5. Maksuti, R. Impact Of The Acicular Ferrite On The Charpy V-Notch Toughness Of Submerged Arc Weld Metal Deposits. International Journal of Scientific \& Engineering Research, Volume 7, Issue 8, August-2016. 1149-1155.

6. Sumardiyanto, D., Susilowati, S. E., \&Cahyo, A. (2018). Effect of Cutting Parameter on Surface Roughness CarbonSteel S45C. Journal of Mechanical Engineering and Automation, 8(1), 1-6.

7. Dehalwar, K. A. V. I. T. A., \& Singh, J. A. G. D. I. S. H. (2015). Current State of Water Management System: Case Review of Bhopal, Madhya Pradesh. International Journal of Civil, Structural, Environmental and Infrastructure Engineering Research 
and Development (IJCSEIERD), 5(6), 35-40.

8. Reddy, K. S., \&Raju, G. Hall Current and Radiation Effects On Mhd Free Convective Heat And Mass Transfer Flow Past An Accelerated Inclined Porous Plate with Thermal Diffusion.

9. Gholap, P. N., \& Shah, R. Modified AodvWith Current Bandwidth Calculation For Mobile Ad Hoc Networks.

10. Gatahun, E. A., Abate, M. G., \&Abyu, D. M. (2016). Current complementary feeding practice among 6-23 months young children, kemabaworeda south ethiopia. International Journal of Food Science and Technology, 6(1), 1-10. 

